Research Article

\title{
Theoretical and Experimental Study on the Mechanism of Instability and Firing Gas in Hard Quartz Sandstone
}

\author{
Jianqiang Liu, ${ }^{1,2}$ Guangpeng Qin $\left(\mathbb{D},{ }^{1,2,3}\right.$ Jing Cao, ${ }^{4}$ Minghua Zhai, ${ }^{3}$ and Yunxin Pei ${ }^{1}$ \\ ${ }^{1}$ College of Resource, Shandong University of Science and Technology, Tai'an, Shandong 271000, China \\ ${ }^{2}$ National Engineering Laboratory for Coalmine Backfilling Mining, Shandong University of Science and Technology, Tai'an, \\ Shandong 271000, China \\ ${ }^{3}$ Shandong Energy Group Co., Ltd., Ji'nan, Shandong 250100, China \\ ${ }^{4}$ College of Finance and Economics, Shandong University of Science and Technology, Tai'an, Shandong 271000, China
}

Correspondence should be addressed to Guangpeng Qin; skd992807@sdust.edu.cn

Received 25 December 2020; Revised 4 March 2021; Accepted 4 April 2021; Published 17 April 2021

Academic Editor: Hualei Zhang

Copyright (C) 2021 Jianqiang Liu et al. This is an open access article distributed under the Creative Commons Attribution License, which permits unrestricted use, distribution, and reproduction in any medium, provided the original work is properly cited.

\begin{abstract}
The upper part of high gas coal seam often has a hard and thick sandstone roof, which provides the condition for the occurrence of gas accident in goaf caused by the friction effect for the sliding and instability of hard quartz sandstone. Based on the engineering background of the 1007 working face of Xiakuotan Coal Mine, the conditions of sliding instability of hard quartz sandstone and the possibility of the friction effect are discussed by combining theoretical analysis with the laboratory test. When the ratio of span to thickness is less than $2 \sim 2.56$, the hard-thick sandstone strata may slip and lose stability. The influence of friction velocity and gas concentration on the induced gas of quartz sandstone is analyzed and compared. The results show that the point spark, the spark beam, and the gas explosion time are inversely proportional to the relative friction velocity, and the intensity of the gas explosion is directly proportional to the gas concentration and the relative friction velocity. This paper provides the basis for the prevention and control of gas disasters in goaf and the control of hard and thick sandstone roof strata under similar engineering geological conditions. It is of great significance to promote the safe and efficient production of coal mines and to ensure the safety of personal and property.
\end{abstract}

\section{Introduction}

As early as the 1880s, the Prussian Coal Mine Gas Commission first proposed the possibility of gas explosion caused by rock friction [1] After summarizing the related accidents of gas detonation in goaf during rock caving in the coal roof, it is concluded that the friction between sandstone and shale and friction between sandstone and sandstone lead to gas-air mixture which is the cause of the accident by U.S. Mining Agency [2]. Golinko et al. [3] It is suggested that the heat accumulated during friction can be transferred from friction particles to nearby explosive carriers. In the study by Ward et al. [4] and Ward Colin et al. [5], in view of the potential risk of rock friction igniting goaf gas in the Australian coal mine, it is concluded that quartz sandstone, siliceous quartz tuff, and iron sulfide rock are more likely to cause gas combustion. Wang et al. [6, 7] suggested that the thermal convection effect caused by rock collision is the cause of gas explosion caused by the rock friction effect. The test carried out by $\mathrm{Qu}$ et al. [8], Qin et al. [9], Wu [10], and Wang et al. [11] showed that the coarse sandstone, quartz sandstone, and other rocks have the possibility of igniting gas under friction. In the study by Xu et al. [12], the effects of quartz content, rock impact angle, height, and rock moisture content on the friction effect of rock ignition gas are analyzed. In the study by $\mathrm{Wu}$ et al. [13], the infrared thermal imaging technology is used to prove that the spark and rising temperature produced during the impact of sedimentary rocks can reach the required temperature for gas ignition. At the same time, in the test carried out by Liu et al. [14], it is found that when the friction temperature of rock reaches $700^{\circ} \mathrm{C}$, the gas concentration will be reduced to 3.25 .

A fine sandstone and quartz sandstone with an average total thickness of about $20.8 \mathrm{~m}$ are covered with a basic top, 
which is shown in Figure 1. The composition is mainly quartz, feldspar, good integrity, hard, and difficult to fall, and the working face strata are columnar.

The working face adopts the mining technology of fully mechanized caving coal mining with strike length $862 \mathrm{~m}$, inclined length $150 \mathrm{~m}$, average thickness of coal seam $5.5 \mathrm{~m}$, and average inclination angle $13^{\circ}$. In April 2013, during the normal mining of the 1007 working face, gas accumulated in goaf due to roof pressure and the instantaneous impact wind pressure brought out the burning gas from the upper corner of the working face resulted in 6 workers being burned. In June of the same year, the working face was unsealed and resumed production for less than half a month, and another similar accident occurred, resulting in a worker being burned; two accidents resulting in the mine being closed for 3 months, and the layout of the working face and the occurrence of the accident are shown in Figure 2.

Sandstone roof and gas are common in coal mines in China. The friction effect caused by sandstone instability and fall and the mechanism of gas explosion in goaf are not completely clear. In this paper, the influence of friction velocity and gas concentration on friction effect-induced gas in goaf is discussed.

\section{Causes and Criterion for the Formation of the Friction Effect of Sliding Instability in the Rock Layer}

After the roof of goaf is broken $\mathrm{O}-\mathrm{X}^{\prime \prime}$, the middle part of the working face begins to sink, and the broken rock blocks squeeze each other to form the horizontal force. Under the influence of the increase of horizontal extrusion pressure, the friction between contact rock blocks increases, and the forces of each rock block reach a relative equilibrium state, forming a three-dimensional occlusal relationship in the space range. The outer surface looks like a beam but essentially an arch fissure "masonry beam" structure, as shown in Figure 3. With the continuous mining process, the roof over the goaf is broken periodically, and the masonry beam structure will also have a "stable-unstable-restable" periodic change process.

When the friction force at the arch foot is less than the gravity of the rock block itself and the shear stress of the overlying load acting on the arch foot, the three-hinged arch structure will be destroyed. The rock block near the coal wall will slip and lose stability, and the overlying strata will fall along the side of the coal wall. In the process of cutting, the relative motion between the broken rock blocks produces the friction effect, and the rock block will also have sliding friction with the unbroken rock block.

As the working face continues to advance, the overlying strata are "O-X" broken, and the broken strata form a threehinged arch beam structure, as shown in Figure 3. When the friction force is the same as the bite point, the balance between the blocks is maintained. When the friction force is less than the shear force, the failure occurs between the broken rock blocks, and then, the friction effect will occur between the rock blocks. The sliding friction force between $\mathrm{A}$ of the rock block and the nonfractured rock block in the direction of the working face $\mathrm{F}$ can be regarded as

$$
F=T f=\frac{q L_{c}^{2}}{2 h_{g}} \tan \varphi .
$$

$T$ is horizontal thrust $(\mathrm{N})$, and $f$ is sliding friction coefficient between rock blocks, and $q$ is the load $(\mathrm{N} / \mathrm{m})$ of overlying strata. $L_{\mathrm{C}}$ is the breakage for strata $(\mathrm{m}) ; h_{g}$ is the thickness of the rock layer; $\varphi$ is the internal friction angle of the rock layer.

The shear force $R$ reaches the maximum at both ends of the support in the masonry beam structure. When the friction force is $F$ less than the shear force $R$, that is, $R=q L_{c}$,

$$
\begin{gathered}
\frac{q L_{c}^{2}}{2 h_{g}} \tan \varphi<q L_{c}, \\
\frac{L_{c}}{h_{g}} \leq 2 \cot \phi .
\end{gathered}
$$

The internal friction angle of mine sandstone rock $\varphi=38-45^{\circ}$ and $\cot \varphi=1-1.28$, that is, when the ratio of breaking size to thickness is less than 2 2.56, the breaking rock block may slip and lose stability.

\section{Experimental Design of the Friction Effect of 3 Quartz Sandstones on Firing Gas}

3.1. Test Equipment. Design and manufacture of the friction effect-gas explosion test box, as shown in Figure 4. Use rated voltage $U=380 \mathrm{~V}$, rated power $P=5.5 \mathrm{~kW}$, and three-phase asynchronous motor with maximum speed $n=\mathrm{r} / \mathrm{min} 2800$. As the power source of the friction effect, select a gas detector with a measuring range of $0 \sim 100$ VOL $\%$ to determine the gas concentration in the box (Figure 4(b)). Before the trial started, the methane monitoring probe is placed in the upper part of the test box to determine the gas concentration in the test box. The gas concentration in the box is read out directly by the main engine outside the box. Use a frequency converter with rated voltage $U=380 \mathrm{~V}$ and rated power $\mathrm{PU}=7.5 \mathrm{~kW}$ (Figure 4(c)) to adjust motor speed, in order to adjust the relative friction velocity between the specimens.

The motor is connected with the bearing in the experimental box through the vehicle coupling, and the motor power is transmitted to the specimen in the experimental box, which can greatly improve the transmission efficiency and the stability of the equipment operation, and at the same time, the external protective shell is installed to ensure the safety of the test process (Figure $4(\mathrm{~d})$ ).

3.2. Selection of Rock Samples and Specimen Processing. Select quartz sandstone ore suitable for easy processing, ore of less than $400 \mathrm{~mm}$, in length width not exceeding $300 \mathrm{~mm}$, and the thickness is about $100 \sim 200 \mathrm{~mm}$. There are no obvious cracks in the ore and has good integrity, as shown in Figure 5. An inner diameter of $40 \mathrm{~mm}$ is processed $120 \mathrm{~mm}$ smooth sandstone ring. The rotating specimen is mainly 


\begin{tabular}{|c|c|c|c|c|c|c|c|c|c|}
\hline No. & $\begin{array}{l}\text { Thickness } \\
\text { (m) }\end{array}$ & $\begin{array}{l}\text { Depth } \\
\text { (m) }\end{array}$ & Formation & Lithology & No. & $\begin{array}{l}\text { Thickness } \\
\text { (m) }\end{array}$ & $\begin{array}{l}\text { Depth } \\
\text { (m) }\end{array}$ & Formation & Lithology \\
\hline 1 & 2.90 & 211.70 & Fine sandstone & 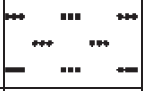 & & & & & 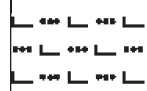 \\
\hline 2 & 4.30 & 216.00 & Sandy mudstone & 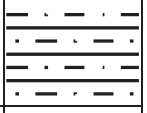 & 9 & 13.90 & 237.00 & Quartz sandstone & 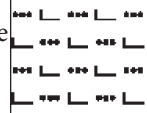 \\
\hline 3 & 1.00 & 217.00 & Siltstone & $-^{-}-{ }^{-}-$ & & & & & - ட … \\
\hline 4 & 2.20 & 219.20 & Sandy mudstone & \begin{tabular}{|l|}
$-\cdots-\dot{ }$ \\
$--\cdots-$ \\
$-\cdots-$ \\
\end{tabular} & \multirow{4}{*}{10} & \multirow{4}{*}{6.85} & \multirow{4}{*}{243.85} & \multirow{4}{*}{ Fine sandstone } & "* \\
\hline & & & & & & & & & 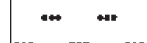 \\
\hline 5 & 0.90 & 220.10 & Fine sandstone & 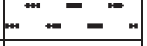 & & & & & $\cdots$ \\
\hline 6 & 1.00 & 221.10 & Sandy mudstone & - $-\cdot-\cdot-$ & & & & & מ. \\
\hline 7 & 0.90 & 220.00 & Fine sandstone & $\ldots$ & \multirow[b]{2}{*}{11} & \multirow[b]{2}{*}{5.50} & \multirow[b]{2}{*}{249.35} & \multirow[b]{2}{*}{ No.10 coal seam } & \\
\hline 8 & 1.10 & 223.10 & Sandy mudstone & $\frac{\cdots-\cdot}{-\cdots \cdot-}$ & & & & & \\
\hline
\end{tabular}

FIgURE 1: Generalised stratigraphic column of the 1007 working face.

fixed by three long bolts of $4 \mathrm{~mm}$ diameter $120^{\circ}$ triangular structure, as shown in Figure 6.

3.3. Test Programme. The experiment mainly studies the influence of friction velocity and gas concentration on the friction of quartz sandstone to ignite gas. The test adopts the control variable method. One of the three factors is the fixed factor and the other is the control factor. The design scheme is as follows.

(1) Influence of different velocities on friction ignition gas of quartz sandstone is studied. Under the condition of gas concentration of $10 \%$ volume fraction, the contact surface velocity is $2 \mathrm{~m} / \mathrm{s}, 4 \mathrm{~m} / \mathrm{s}, 6 \mathrm{~m} / \mathrm{s}, 8 \mathrm{~m} / \mathrm{s}$, and $10 \mathrm{~m} / \mathrm{s}$, respectively. (2) The influence of different gas concentrations on the friction ignition gas of quartz sandstone is studied. Under the condition that the indirect contact velocity of the rock block is $6 \mathrm{~m} / \mathrm{s}$, the volume fraction of gas concentration is $4.3 \%, 6 \%, 8.6 \%, 10.3 \%$, and $12 \%$, respectively.

\section{Effect of Friction Speed on the Friction Effect of Firing Gas}

In order to study the effect of friction velocity on the ignition gas of the friction effect, the gas concentration is 10 and the friction velocity is $2 \mathrm{~m} / \mathrm{s}, 4 \mathrm{~m} / \mathrm{s}, 6 \mathrm{~m} / \mathrm{s}, 8 \mathrm{~m} / \mathrm{s}$, and $10 \mathrm{~m} / \mathrm{s}$, respectively. Under each friction velocity condition, the typical test (friction spark appearance, spark beam appearance, and gas explosion) phenomenon is shown in Figure 7.

When the friction velocity is $2 \mathrm{~m} / \mathrm{s}$, as shown in Figure $7(\mathrm{a})$, in the friction test between the specimens starting from $0 \mathrm{~s}$ until $1.6533 \mathrm{~s}$, a slight spark begins to occur between the rotating specimen and the friction specimen. The spark lasted until the end of the $50 \mathrm{~s}$ test, and no gas combustion explosion occurred during the period.

As shown in Figure 7(b), when the friction velocity is $4 \mathrm{~m} / \mathrm{s}$, the point spark formed by friction between the rotating specimen is through $1.503 \mathrm{~s}$, and it is more obvious than the point spark of $2 \mathrm{~m} / \mathrm{s}$, and until 39.0947, the gas was combusted in the test box.

As shown in Figure $7(\mathrm{c})$, when the friction velocity is $6 \mathrm{~m} / \mathrm{s}$, the rotating specimen and the friction specimen pass through the friction forming point spark of $2.2044 \mathrm{~s}$. And, at 22.2945 s, the gas in the test box exploded.

As shown in Figure $7(\mathrm{~d})$, when the friction velocity is $8 \mathrm{~m} / \mathrm{s}$, the gas in the test box explodes when the rotating specimen and the friction specimen pass through the friction forming point spark of $5.6446 \mathrm{~s}$.

As shown in Figure 7(e), when the friction velocity is $10 \mathrm{~m} / \mathrm{s}$, the rotating specimen and the friction specimen pass through $4.8764 \mathrm{~s}$ friction-forming point spark, and the quartz sandstone specimen only passes through $8.83 \mathrm{~s}$ mutual friction test box gas explosion.

The time nodes of typical test phenomena during different friction velocity tests are shown in Table 1 and Figure 8 .

From Table 1 and Figures 7 and 8, it can be seen that, under other conditions, the mechanical energy of friction between quartz sandstone specimens is converted into heat energy. When the velocity increases, the heat energy converted in unit time increases, the formation time of friction spark is shortened, and the heat energy generated by friction is transmitted to gas by heat radiation. If the friction speed is $2 \mathrm{~m} / \mathrm{s}$, the low friction speed makes the low internal heat energy density of gas-air mixture gas not enough to ignite the gas in the test box, so there is no gas combustion and explosion in this group of tests. With the increase of friction speed, the time from spark to ignition gas is reduced from $37.5917 \mathrm{~s}$ to $4.7522 \mathrm{~s}$, which is due to the increase of relative friction speed, the increase of friction work per unit time, the increase of heat energy conversion, the rapid rise of friction surface temperature, and the increase of energy density of gas containing gas in unit volume near the friction surface. To sum up, after the increase of friction speed, the energy converted from mechanical energy to heat energy increases 


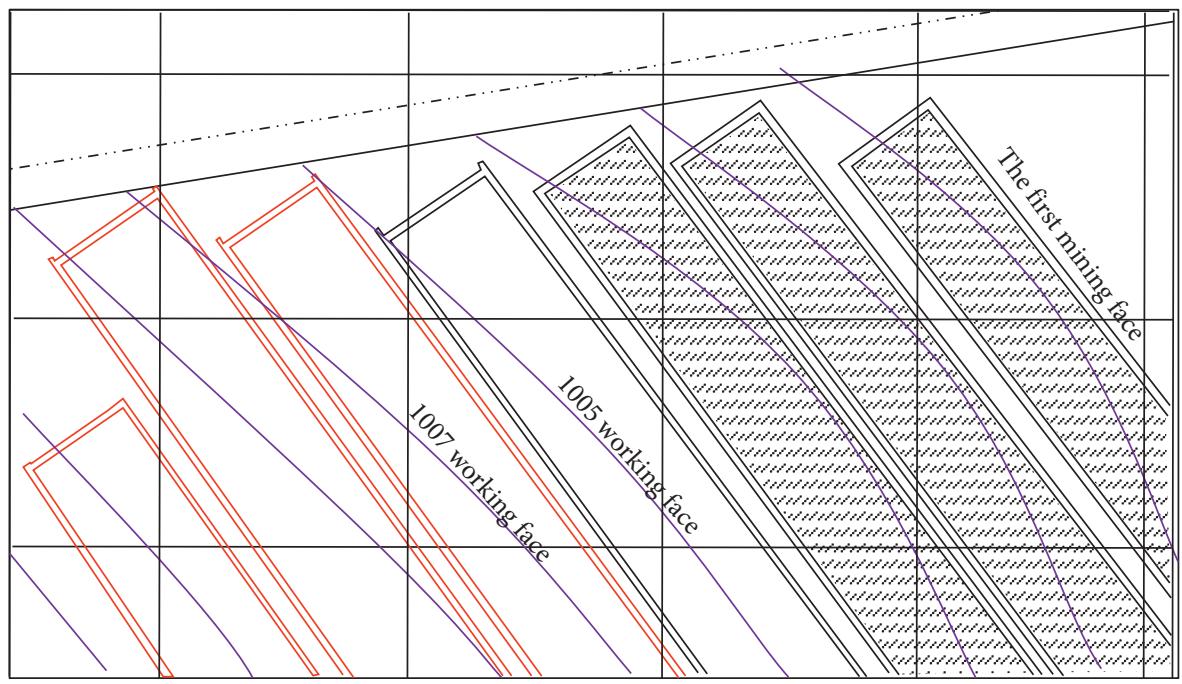

(a)

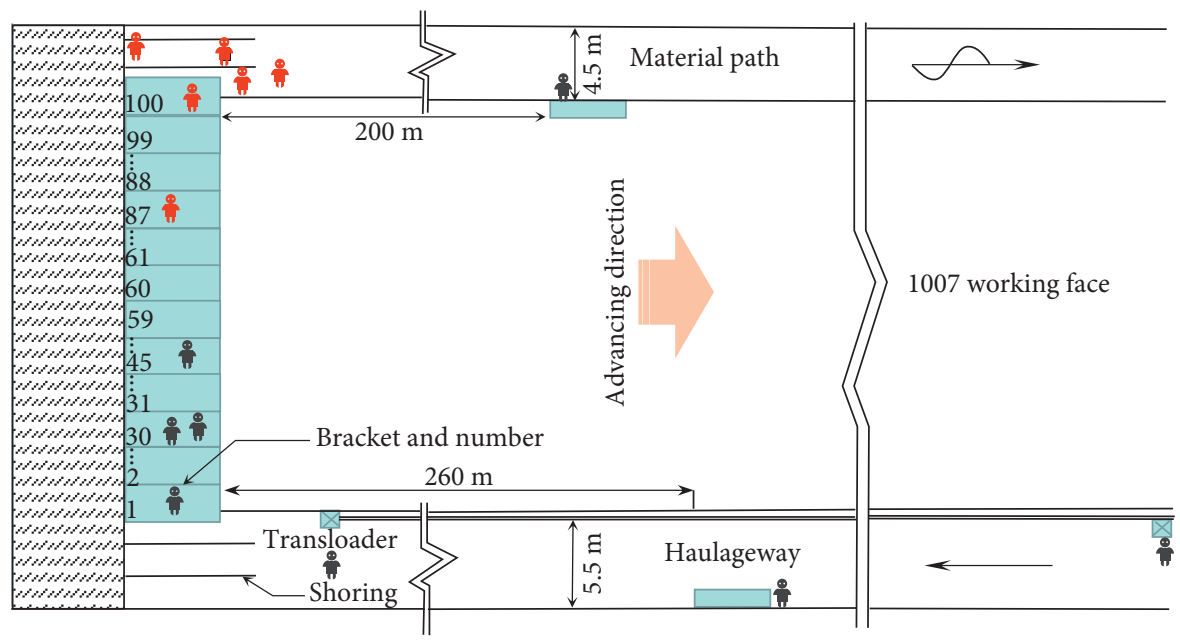

- Injured member

\% Staff member

(b)

FIgURE 2: Layout of the working face and incidents' indication. (a) Working face layout. (b) Schematic illustration of the first accident site.

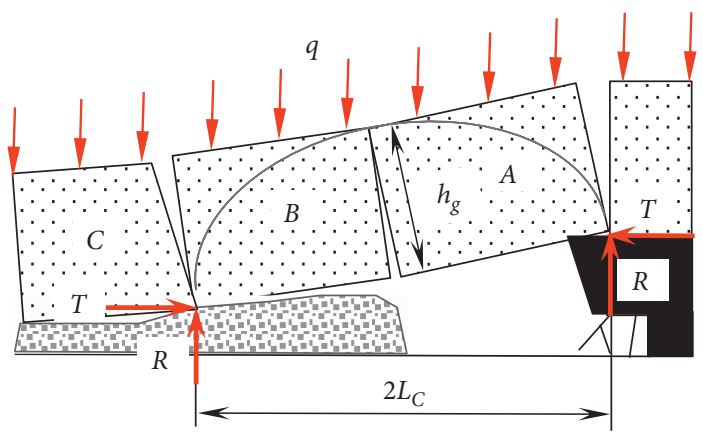

Figure 3: Schematic diagram of the overburden broken structure in stope. 


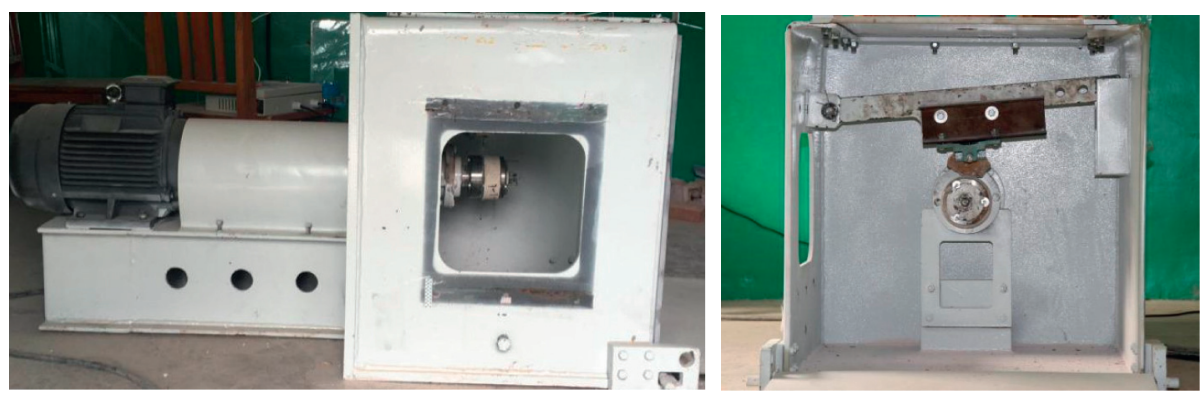

(a)

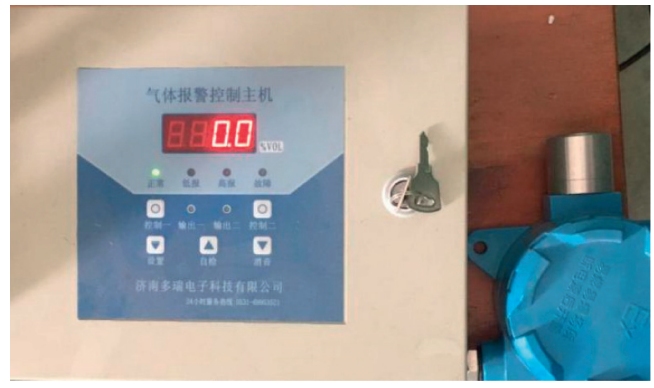

(b)

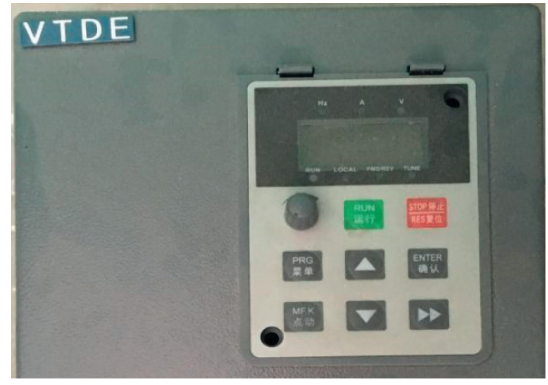

(c)

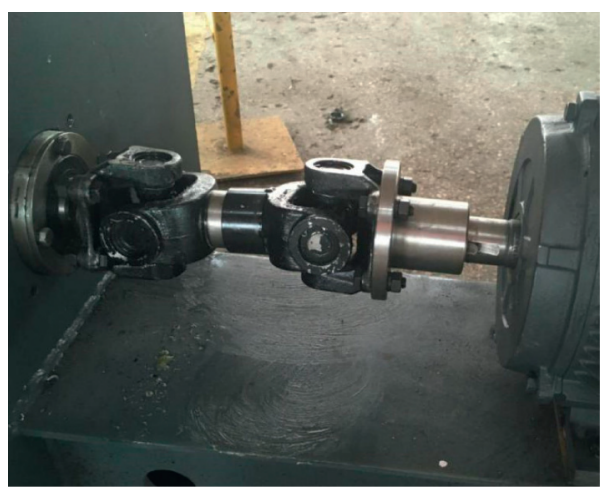

(d)

Figure 4: Test equipment. (a) Friction test box. (b) Gas monitoring device. (c) Speed control device. (d) Connection box.

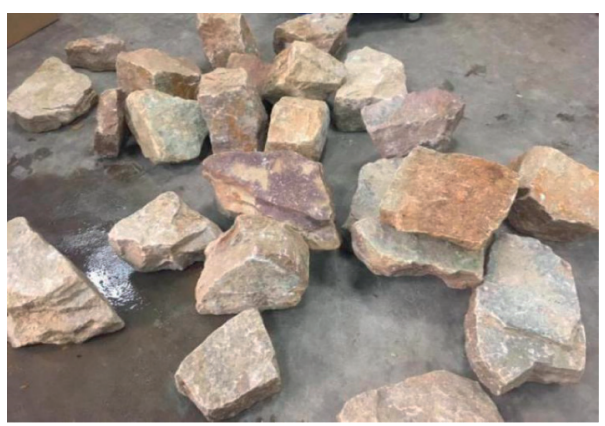

FIGURE 5: Quartz sandstone rocks. 


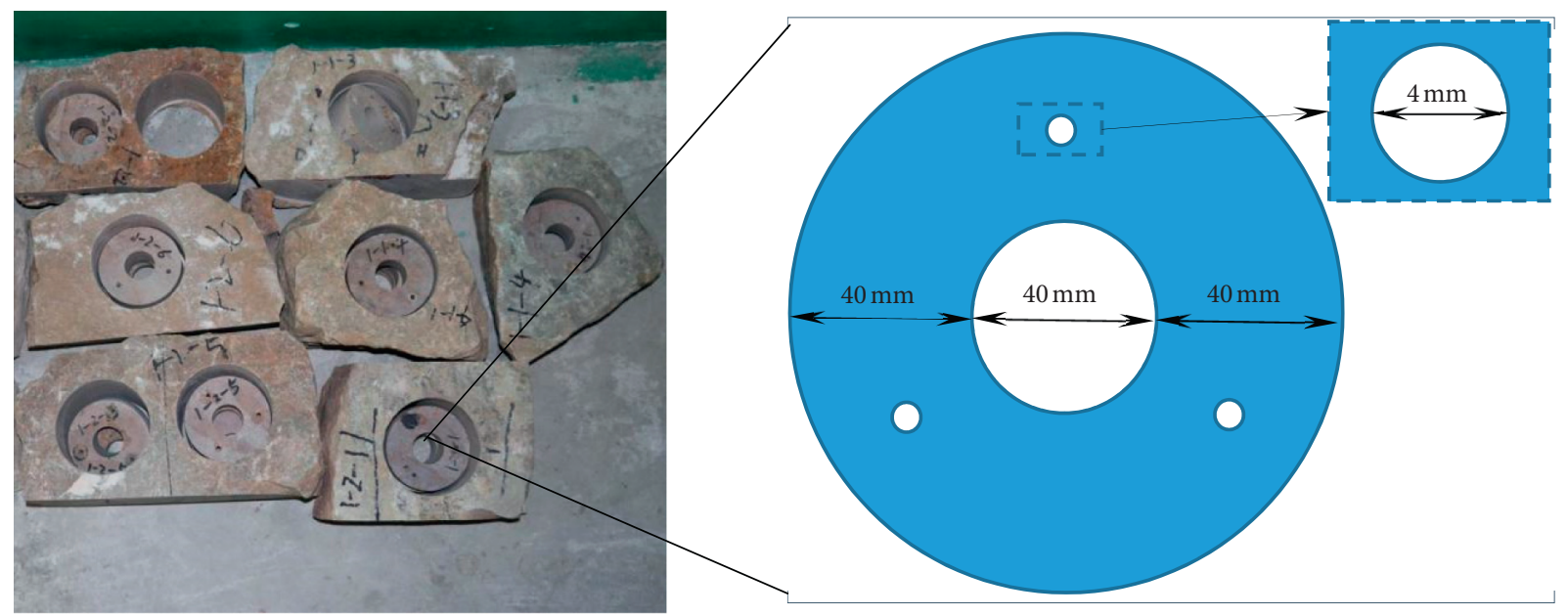

Figure 6: Test specimens.

in unit time, which accelerates the reaction of gas and plays a key role in igniting gas by the friction effect.

\section{Effect of Gas Concentration on the Friction Effect of Firing Gas}

To study the influence of gas concentration on the friction effect of igniting gas, the friction velocity is $6 \mathrm{~m} / \mathrm{s}$, the contact surface pressure is $0.375 \mathrm{MPa}$, and the gas concentration is $4.3 \%, 6 \%$, $8.6 \%, 10.3 \%$, and $12 \%$, respectively. The typical phenomena during the test are shown in Figure 9.

The time node of the typical test phenomenon is shown in Table 2.

As shown in Figure 9(a), when the gas concentration in the test box is $4.3 \%, 2.338 \mathrm{~s}$ is passed from the beginning of the test to the first friction spark formed by the friction between quartz sandstone and each other. When the test entered $4.3253 \mathrm{~s}$, the spark beam was formed by friction between quartz sandstone, and the spark beam appeared continuously and stably during the subsequent test. The total experimental time is $35 \mathrm{~s}$, but because the gas concentration is low, the gas ignition concentration is not reached, and the gas in the test box does not burn.

As shown in Figure 9(b), when the gas concentration in the test box is $6.0 \%$, only $0.2171 \mathrm{~s}$ after the start of the test forms a point spark and $1.6533 \mathrm{~s}$ later forms a spark beam and maintains a relatively stable state after the start of the test. A total of 32 tests were carried out. Although the gas concentration has reached the explosion and combustion concentration, the gas in the test box did not burn or explode because of the low ignition energy of the friction effect.

As shown in Figure 9(c), when the gas concentration in the test box is $8.6 \%$, it is taken as $4.676 \mathrm{~s}$ for the point spark generation from the start of the test, and after 5.9786 s from the test start, the spark beam is formed and remains in a relatively stable state. At the time of $7.014 \mathrm{~s}$, the gas in the test box exploded, forming a group of obvious flame, and the explosion airflow broke through the plastic film at the vent.

When the gas concentration in the test box is $10.3 \%$, as shown in Figure 9(d), after 5.4943 s, it forms a spark beam and maintains a relatively stable state from the start of the test device to the point spark generation after the 2.4883 test. At the time of $6.2458 \mathrm{~s}$, the gas in the test box explodes, forming a bright flame, and the explosion airflow breaks through the film at the vent and forms a flame impact front.

As shown in Figure 9(e), when the gas concentration in the test box is $12 \%$, the spark beam is formed from the start of the test device to the point spark generation after $2.4883 \mathrm{~s}$, and $6.2959 \mathrm{~s}$ after the start of the test, it remains in a relatively stable state. At the time of $7.9826 \mathrm{~s}$, the gas in the test box explodes, forming a bright flame, and the explosion airflow breaks through the film at the vent and forms a flame impact front.

Gas explosion is a kind of heat-chain reaction. The friction heat effect of the quartz specimen provides ignition energy stably. When the gas analysis absorbs the heat effect energy to a certain extent, the molecular chain participating in the reaction will break, dissolve into two or more free radicals and becomes a continuous activation center. Under suitable conditions, free radicals can further decompose and produce two or more free radicals. This continuous cycle, more and more free radicals, the speed of chemical reaction is also faster and faster. When the gas concentration increases, the number of molecules in the test box increases, and when the reaction conditions are reached, the molecules produce more free radicals, which leads to a more intense reaction and a decrease in the time taken for the reaction.

Therefore, after the gas concentration increases, the number of gas molecules in the test box increases. After the reaction conditions are reached, the number of participating reaction molecules in unit volume increases, the release energy increases, the energy density increases, the initial reaction time is shortened, and the intensity of chemical reaction is increased. When the ignition concentration of methane is reached by quartz sandstone friction in the methane-air mixture gas, a small volume of flame center with high temperature and high free radical concentration can be produced in the mixture gas. This flame center initiates a chemical reaction flow and propagates to the adjacent unburned gas with the 


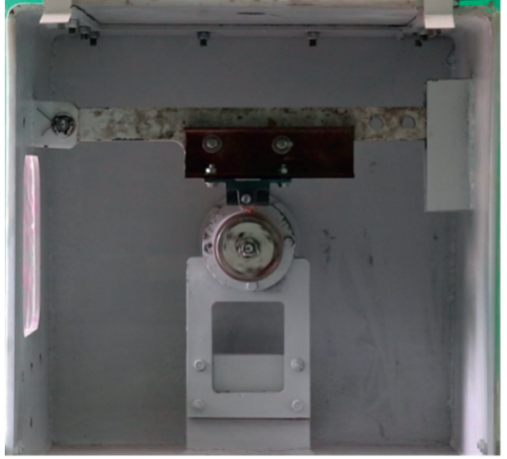

$1.6533 \mathrm{~s}$

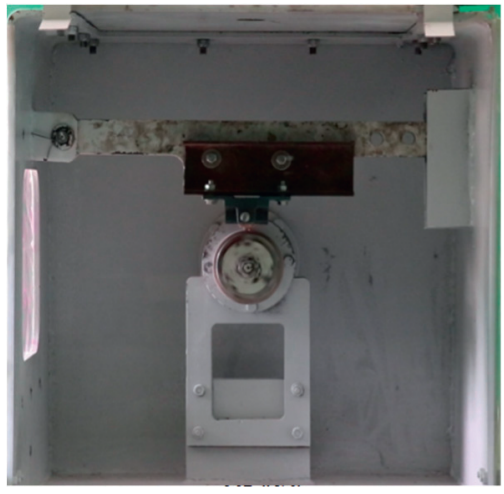

$1.503 \mathrm{~s}$

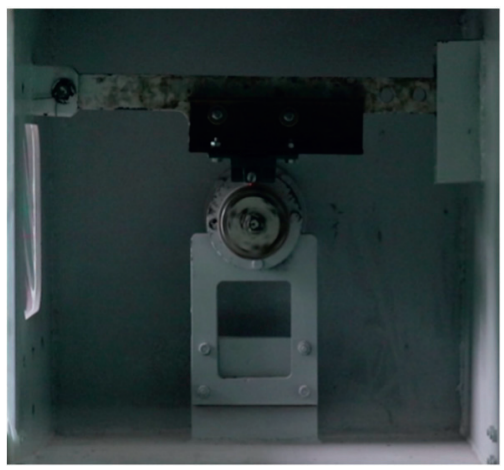

$1.837 \mathrm{~s}$

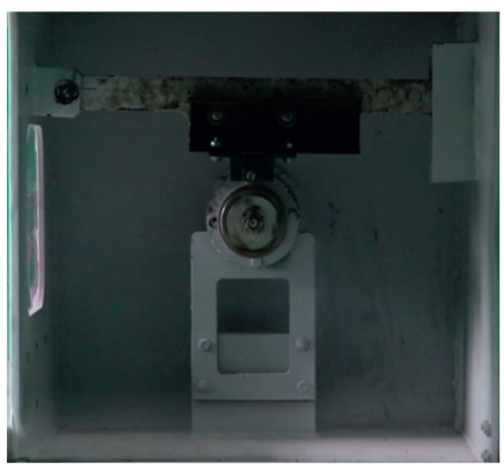

$4.4088 \mathrm{~s}$

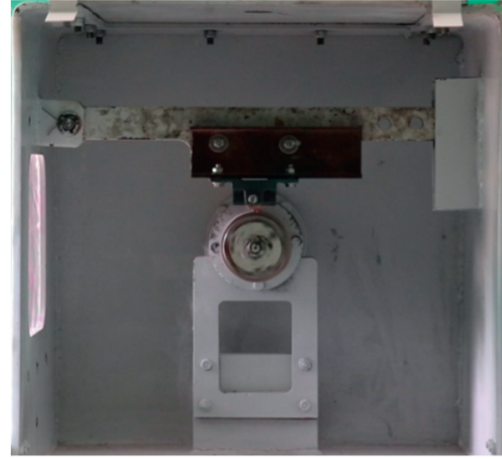

No fire bouquet

(a)

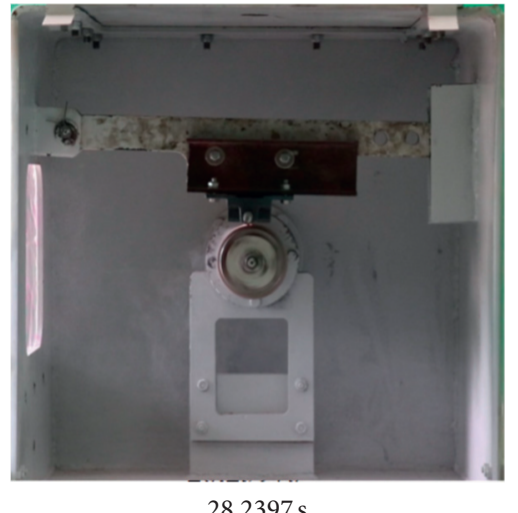

(b)

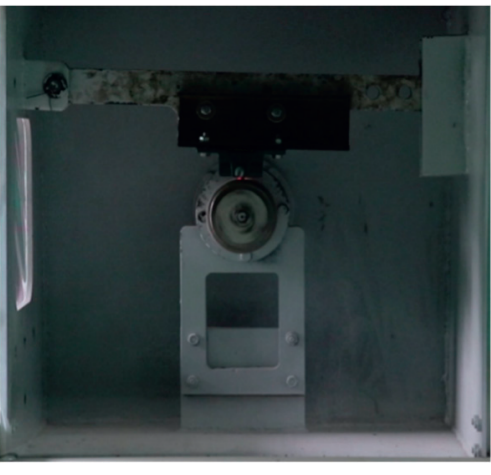

$4.5758 \mathrm{~s}$

(c)

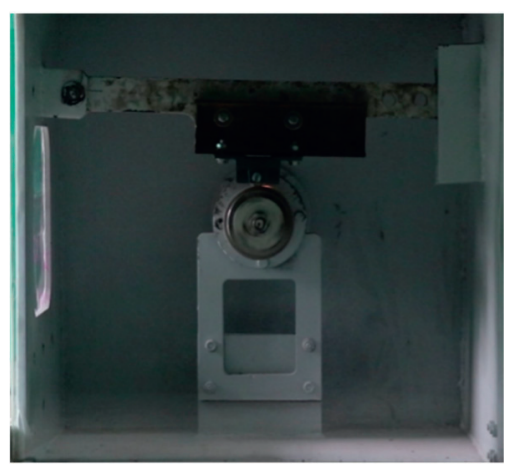

$5.6446 \mathrm{~s}$

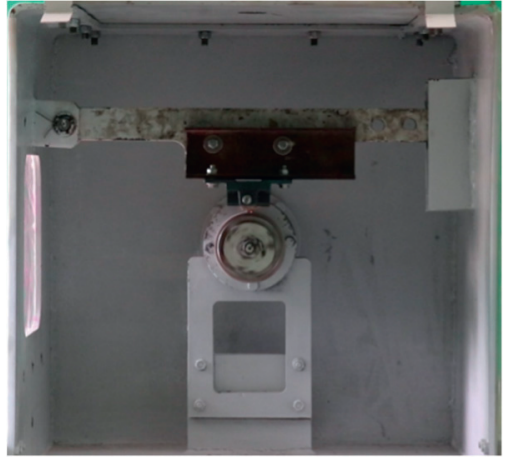

No gas explosion

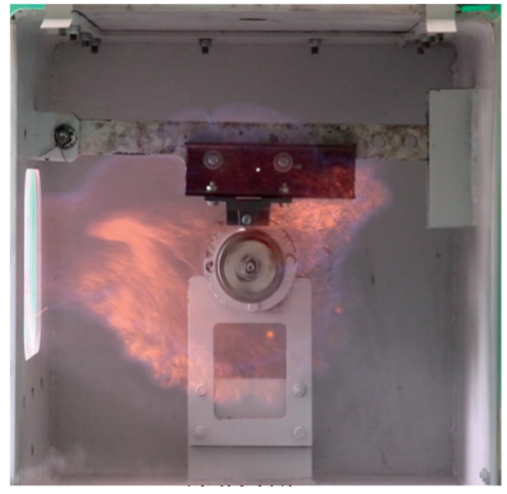

$39.0947 \mathrm{~s}$

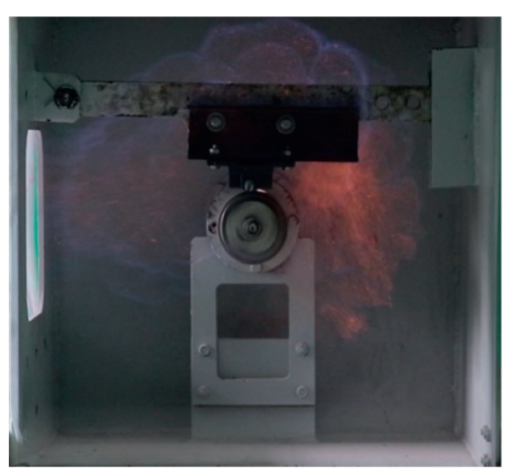

$22.2945 \mathrm{~s}$

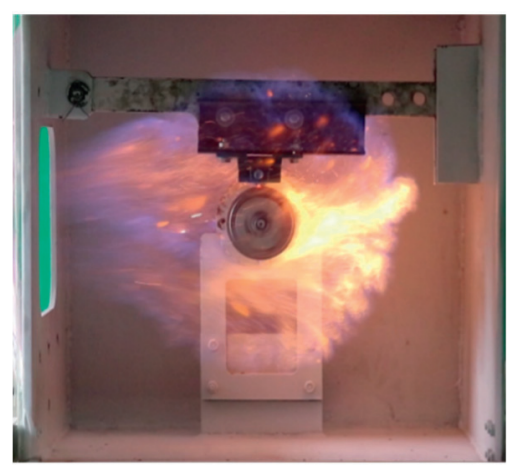

$8.9679 \mathrm{~s}$

(d)

Figure 7: Continued. 


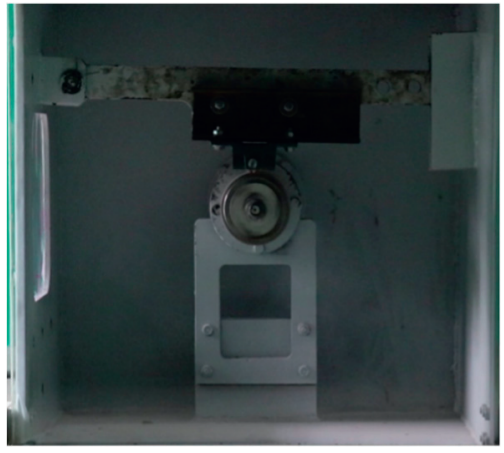

$4.0748 \mathrm{~s}$

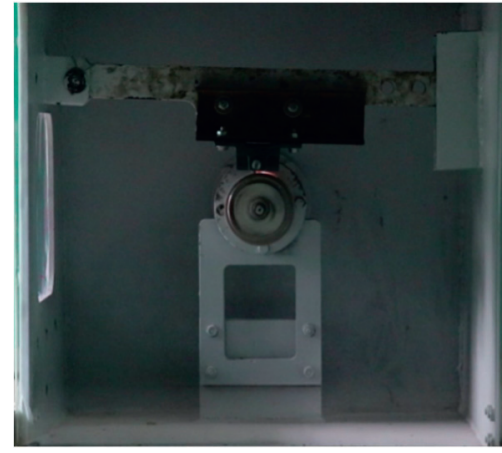

$5.678 \mathrm{~s}$

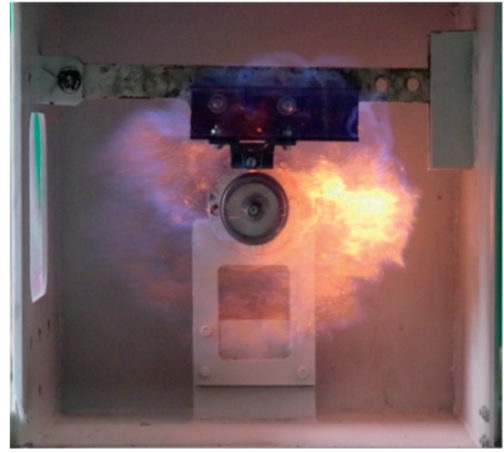

$8.83 \mathrm{~s}$

(e)

Figure 7: Typical experimental results of different friction velocities. (a) $v=2 \mathrm{~m} / \mathrm{s}$. (b) $v=4 \mathrm{~m} / \mathrm{s}$. (c) $v=6 \mathrm{~m} / \mathrm{s}$. (d) $v=8 \mathrm{~m} / \mathrm{s}$. (e) $v=10 \mathrm{~m} / \mathrm{s}$.

TABle 1: Time of occurrence of point sparks at different friction velocities and time of gas explosion.

\begin{tabular}{|c|c|c|c|c|c|}
\hline Friction velocity & $v=2 \mathrm{~m} / \mathrm{s}$ & $v=4 \mathrm{~m} / \mathrm{s}$ & $v=6 \mathrm{~m} / \mathrm{s}$ & $v=8 \mathrm{~m} / \mathrm{s}$ & $v=10 \mathrm{~m} / \mathrm{s}$ \\
\hline Formative time of fire spark (s) & 1.6533 & 1.503 & 1.837 & 4.4088 & 4.0748 \\
\hline Formative time of fire bouquet (s) & No fire bouquet & 28.2397 & 4.5758 & 5.6446 & 5.678 \\
\hline Gas explosion time (s) & No gas explosion & 39.0947 & 22.2945 & 8.9679 & 8.83 \\
\hline
\end{tabular}

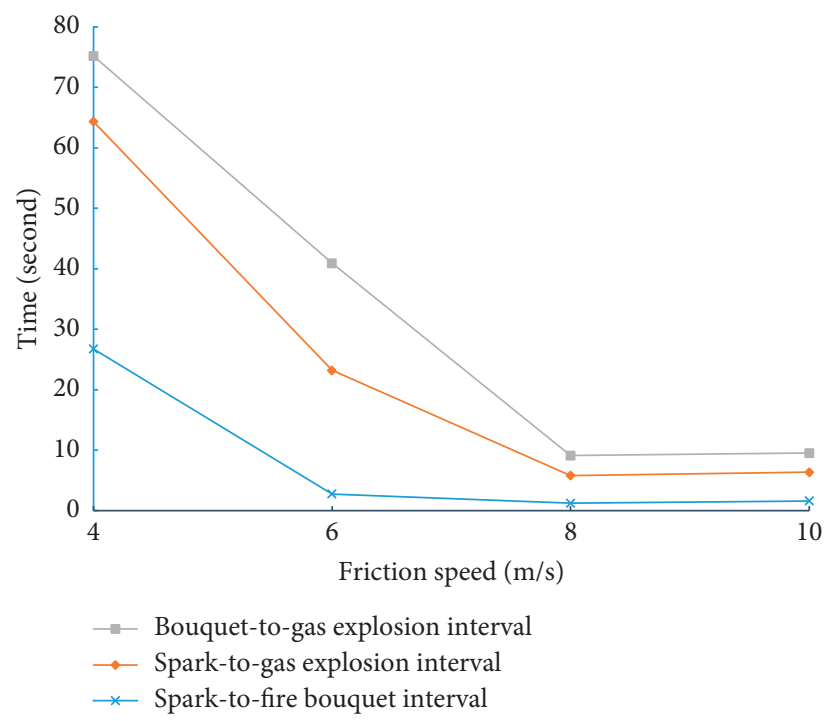

FIGURE 8: Time node information of typical test phenomena.

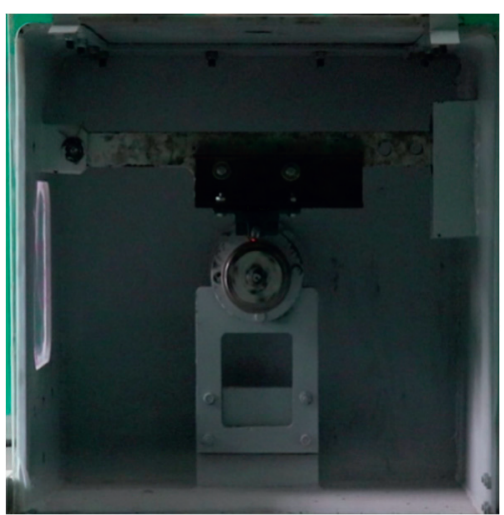

$2.338 \mathrm{~s}$

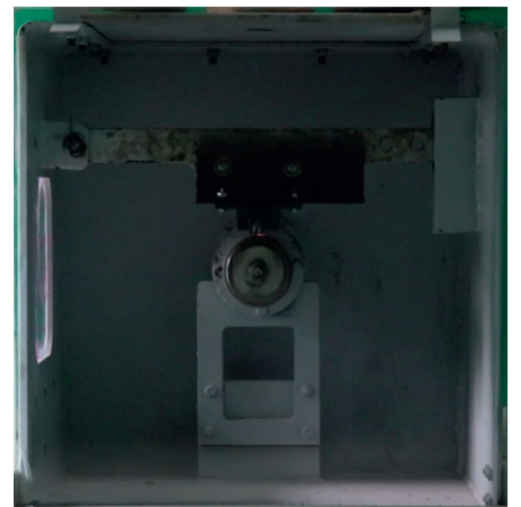

$4.3253 \mathrm{~s}$

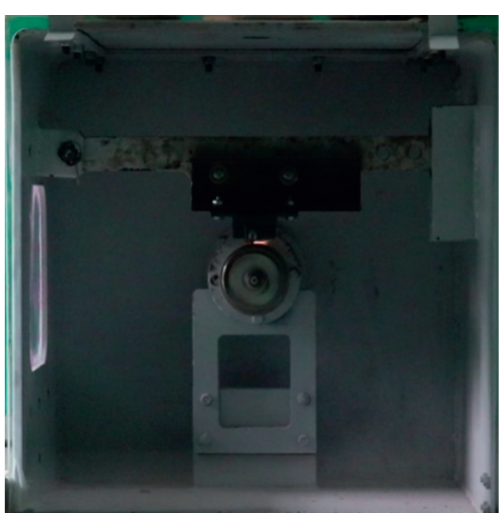

No gas explosion

(a)

Figure 9: Continued. 


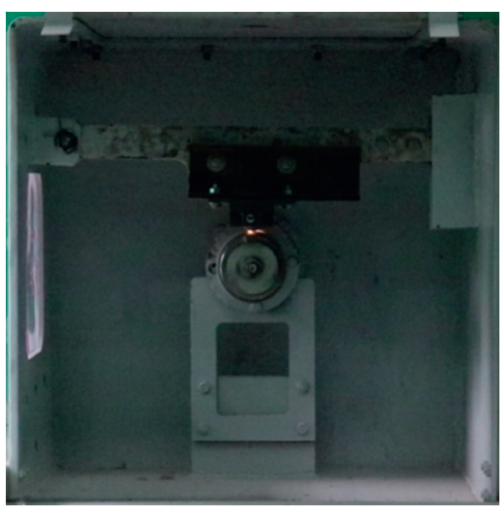

$0.2171 \mathrm{~s}$

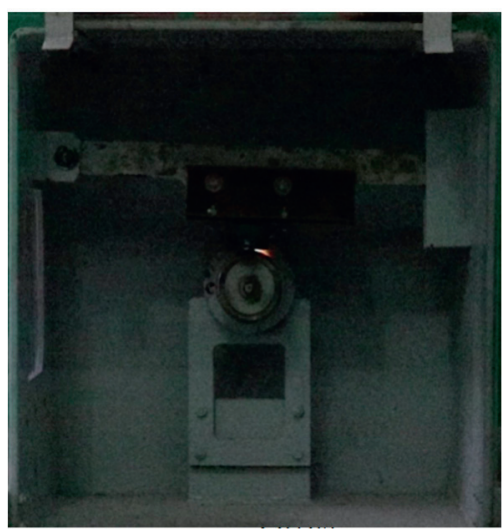

$4.676 \mathrm{~s}$

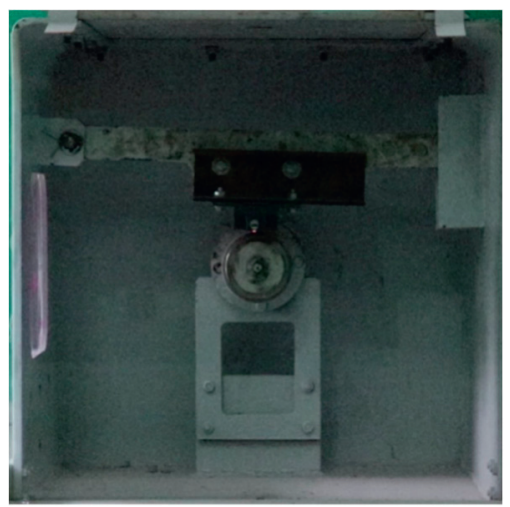

$2.4883 \mathrm{~s}$

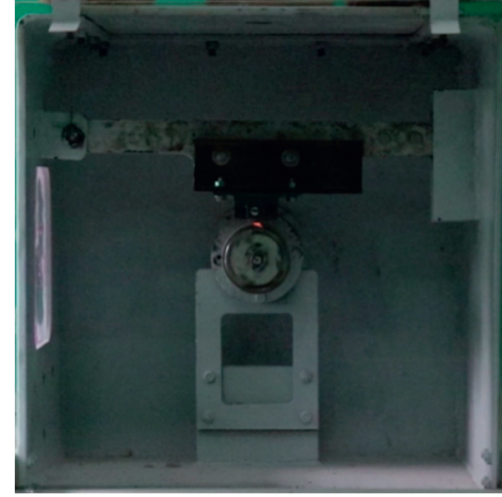

$1.6533 \mathrm{~s}$

(b)

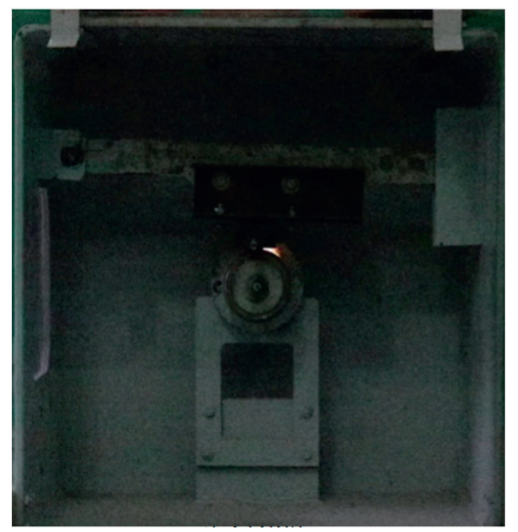

$5.9786 \mathrm{~s}$

(c)

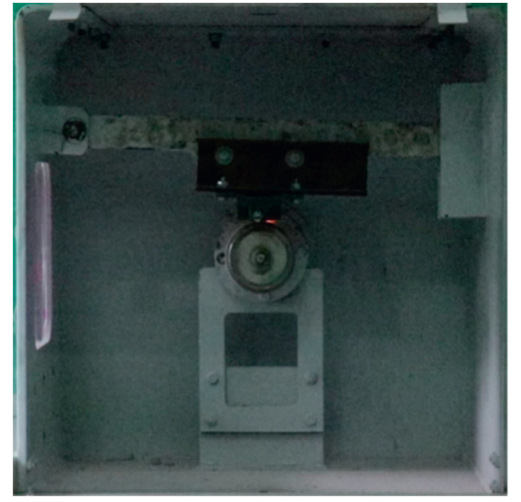

$5.4943 \mathrm{~s}$

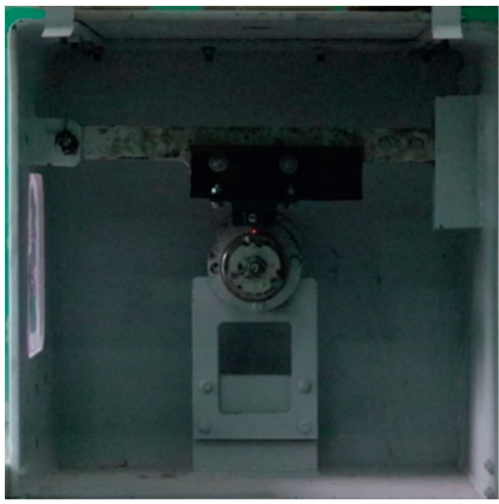

No gas explosion

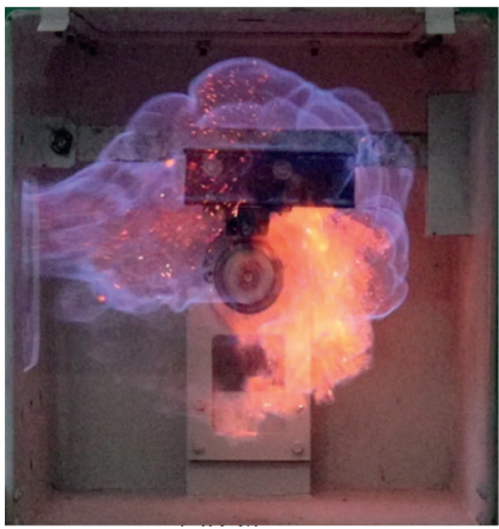

$7.014 \mathrm{~s}$

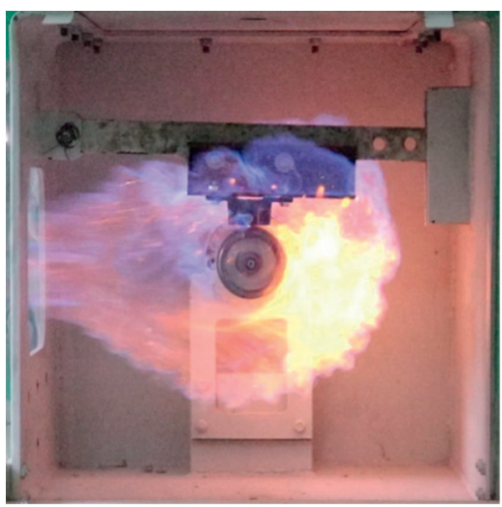

$6.2458 \mathrm{~s}$

(d)

Figure 9: Continued. 


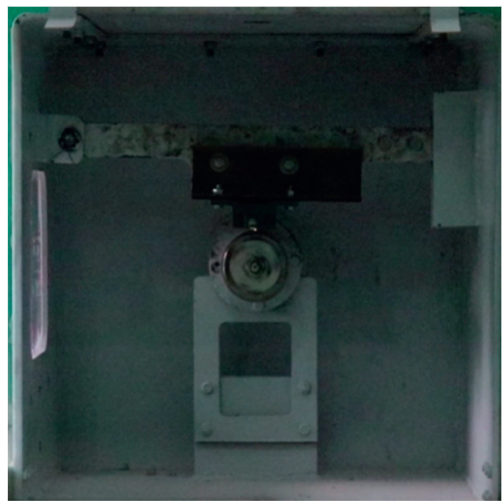

$2.4883 \mathrm{~s}$

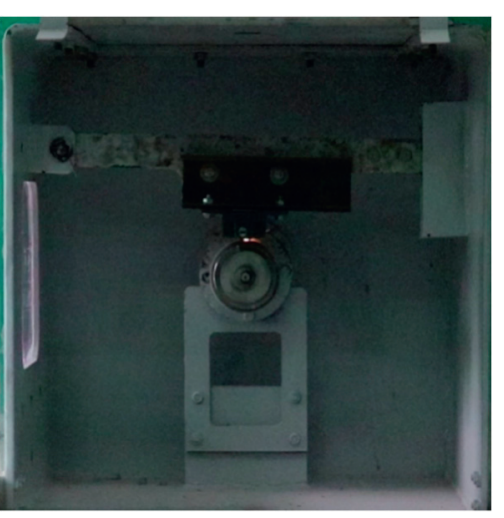

$6.2959 \mathrm{~s}$

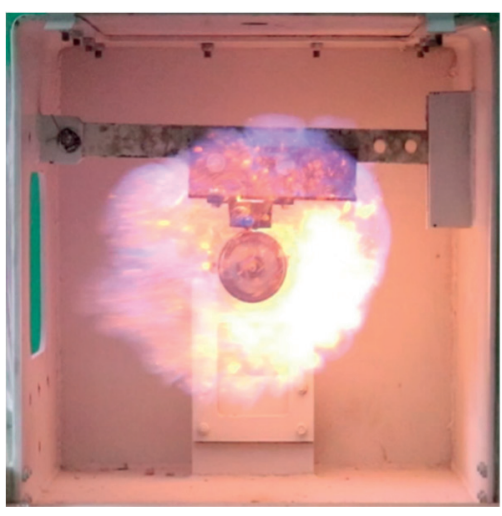

$7.9826 \mathrm{~s}$

(e)

Figure 9: Typical experimental phenomenon of different methane concentrations. (a) 4.3\% VOL. (b) 6.0\% VOL. (c) $8.6 \%$ VOL. (d) $10.3 \%$ VOL. (e) $12.0 \%$ VOL.

TABLE 2: Statistics of point spark, spark beam, and reaction time node of gas explosion at different gas concentrations.

\begin{tabular}{|c|c|c|c|c|c|}
\hline Gas concentration & VOL $\%=4.3 \%$ & VOL $\%=6 \%$ & VOL $\%=8.6 \%$ & VOL $\%=10.3 \%$ & VOL $\%=12 \%$ \\
\hline Formative time of fire spark (s) & 2.338 & 0.2171 & 4.676 & 2.4883 & 2.4883 \\
\hline Formative time of fire bouquet (s) & 4.3253 & 1.6533 & 5.9786 & 5.4943 & 6.2959 \\
\hline Gas explosion time $(\mathrm{s})$ & No gas explosion & No gas explosion & 7.014 & 6.2458 & 7.9826 \\
\hline
\end{tabular}

help of heat and free radical diffusion. Thus, the methane gas in the test box is all involved in the combustion explosion reaction.

\section{Main Conclusions}

Through the comparison of the above ten groups of tests, it can be seen that the relative friction velocity has the most direct and intuitive influence on the test among the two influencing factors of friction velocity and gas concentration. For different gas concentrations, when the relative friction velocity is constant, the formation time of the friction point spark and spark beam is still affected by the parameters of the specimen itself, but the ignition energy of the rock friction heat effect is relatively low relative to other ignition modes. Therefore, the prevention and control of this kind of accidents should be placed in the control of coal seam gas:

(1) When the ratio of span to thickness is less than $2 \sim 2.56$, the hard-thick sandstone strata may slip and become unstable, and severe relative friction will occur between the broken rock blocks.

(2) With the increase of the friction velocity of the sandstone rock mass, the mechanical energy is converted into the heat energy rate. When the gas concentration is suitable, the time of spark, spark beam, and gas combustion explosion is shortened. The relative friction velocity is the key factor of the friction effect.

(3) The test results show that the ignition energy of the friction heat effect of rock is lower than that of other ignition methods, and the friction heat effect cannot be ignited even if the gas concentration is suitable.

\section{Data Availability}

The data used to support the findings of this study are available from the corresponding author upon request.

\section{Conflicts of Interest}

The authors declare that they have no conflicts of interest.

\section{Acknowledgments}

This study was sponsored by the Shandong Provincial Key R\&D Plan of China (Grant no. 2019SDZY034-1), Engineering Laboratory of Deep Mine Rockburst Disaster Assessment Open Project (LMYK2020007), National Natural Science Foundation of China (Grant nos. 51504145 and 51804182), and Shandong Provincial Institute of Science and Technology Plan (Grant no. J17KB041). The authors are grateful for their support.

\section{References}

[1] R. Hauke, "Translation by Fu Guo, Circuit ignition characteristic of intrinsic safety and high frequency-higher than industrial alternating current frequency," Electric Explosion Protection, vol. 1, pp. 30-34, 2005.

[2] L. Milford and A. G. K. Skow, Maurice Deul. Creating a Safer Environment in U.S.Coal Mines: the Bureau of Mines Methane Control Program, 1964, U.S.Dept. of the Interior, Bureau of Mines, Washington, DC, USA, 1980.

[3] Y. Golinko, Y. Y. Lebedev, and Y. Ye, "Estimation of frictional sparking effect on firedamp inflammation during fragmentation of as-saturated rock massif," Naukovyi Visnyk Natsionalnoho Hirnychoho Universytetu, vol. 6, pp. 31-37, 2014. 
[4] C. R. Ward, A. Crouch, and D. R. Cohen, "Identification of potential for methane ignition by rock friction in Australian coal mines," International Journal of Coal Geology, vol. 45, no. 2-3, pp. 91-103, 2001.

[5] R. Ward Colin, D. Cohen, P. Drago, C. Anton, S. Stan, and P. Dutta, "Assessment of methane ignition potential by frictional processes from Australian coal mine rocks," Mining Science Ettechnology, vol. 13, no. 2, pp. 183-206, 1991.

[6] J. Wang, J. Wang, J. Shen et al., "Theory analysis of gas hazard incident caused by roof caving," Journal of Mining \&Safety Engineering, vol. 23, no. 4, pp. 379-382, 2006, in Chinese.

[7] J. Wang, J. Wang, J. Shen et al., "Experimental research on gas hazard incident caused by roof collapse," Journal of Mining ¿Safety Engineering, vol. 24, no. 1, pp. 8-11, 2007, in Chinese.

[8] Q. Qu, J. Xu, W. Ma et al., "Experimental study on gas explosion detonated by the rock friction sparks," Journal of China Coal Society, vol. 31, no. 4, pp. 466-469, 2006, in Chinese.

[9] Y. Qin, W. Jiang, and X. Wang, "Determination of ignition source of gob gas explosion (burning)," Safety in Coal Mine, vol. 36, no. 7, pp. 35-37, 2005, in Chinese.

[10] Y. Wu, "Research on prevention of gas dust accidents caused by frictional sparks," China Coal, vol. 28, no. 5, pp. 50-52, 2002, in Chinese.

[11] Y. Wang, W. Jiang, D. Niu et al., "Experimental study on gas explosion ignited by the rock friction," Safety in Coal Mine, vol. 33, no. 12, pp. 8-10, 2002, in Chinese.

[12] J. Xu, R. Zhang, and Y. Beijian, "Study on gas explosion induced by impact-friction sparks during roof collapse with fully-mechanized top-coal caving mining," Journal of China University of Mining \& Technology, vol. 36, no. 1, pp. 12-16, 2007, in Chinese.

[13] Y. Wu, L. Wu, S. Zhong et al., "Experimental exploration to gas explosion induced by rock impact," Journal of China Coal Society, vol. 30, no. 3, pp. 278-282, 2005, in Chinese.

[14] Z. Liu, C. Li, L. Zhang, R. Liu, and Z. Xu, "Analysis on characters of fire source of combustible gas exploration in work-out area," Coal Technology, vol. 26, no. 9, pp. 67-69, 2007, in Chinese. 